\title{
Multi-objective Optimization in Turning Operation of AISI 1055 Steel Using DEAR Method
}

\author{
S. Nguyen Honga, U. Vo Thi Nhub,* \\ a Center for Mechanical Engineering, Hanoi University of Industry, Hanoi City, Vietnam. \\ ${ }^{\mathrm{b}}$ Faculty of Mechanical Engineering, Hanoi University of Industry, Hanoi City, Vietnam.
}

Keywords:

Turning AISI 1055 steel

Multi-objective optimization

Surface roughness

Cutting force

MRR

Taguchi

DEAR

* Corresponding author:

Vo Thi Nhu Uyen

E-mail:vothinhuuyen@haui.edu.vn

Received: 17 November 2020

Revised: 15 December 2020

Accepted: 3 January 2021

\begin{abstract}
A B S T R A C T
This paper presents a study on multi-objective optimization of turning process AISI 1055 steel. It designs 9 experiments (L9) for a Taguchi test series matrix. The four parameters of input include spindle speed, feed rate, depth of cut, tool nose radius. The AISI 1055 steel machining operation experiments are carried out based on the matrix created. They are performed on a conventional lathe. The factors considered for evaluating the machining quality include surface roughness, cutting force in $X, Y, Z$ directions and material removal rate (MRR). First, the research is carried out to identify the impact of the input parameters on the output parameters. Analysis of experimental results show that spindle speed significantly affects all three components of cutting force, but slightly influences the surface roughness. Regarding feed rate, this is the parameter that has a strong effect on surface roughness and cutting force Fx but not on the cutting force Fy and Fz. Meanwhile, the depth of cut has a considerable influence on the force in the $x$ and $y$ directions but a limited impact on the surface roughness and the force in the $z$ direction. Similar to the cutting speed, the tool nose radius is noticeable to all three components of the cutting force and negligible to surface roughness. The second aim of this study is to determine the value of the cutting parameters to achieve the minimum of surface roughness and cutting force and the maximum of MRR. The Data Envelopment Analysis-based Ranking (Dear) method is applied to solve multi-objective problems. The paper identified the optimum values of spindle speed, feed rate, depth of cut and tool nose radius are $910 \mathrm{rev} / \mathrm{min}, 0.194 \mathrm{~mm} / \mathrm{rev}, 0.2 \mathrm{~mm}$ and $0.2 \mathrm{~mm}$, respectively.
\end{abstract}

(C) 2021 Published by Faculty of Engineering

\section{INTRODUCTION}

Turning is the most common method of cutting machining. Turning workload accounts for $40 \%$ of the total machining and the number of lathes makes up $25-35 \%$ of total machines in a cutting workshop [1].
Many studies are conducted for optimizing the turning operation in order to improve the efficiency of the machining process by different methods such as: using the hybrid algorithm of artificial Bee Colony combined with response surface methodology (RSM) to define optimal values of cutting parameters to achieve minimum 
value of surface roughness [2]; applying the hybrid whale optimization algorithm combined with the central composite design (CCD) matrix to determine the optimal value of the cutting parameters with the aim of increasing $M R R$ and reducing surface roughness, cutting heat and cutting force [3].

Besides, some research on turning process optimization has been carried out using the Taguchi method. When turning aluminum workpieces, to reach the minimum of surface roughness, the optimal value of cutting speed, feed rate and depth of cut are $35 \mathrm{~m} / \mathrm{min}, 0.15$ $\mathrm{mm} / \mathrm{rev}$ and $1.25 \mathrm{~mm}$ respectively [4]. For Polyethylene materials, surface roughness will be minimized when turning if the cutting speed, feed rate, depth of cut and tool nose radius are 213.88 $\mathrm{m} / \mathrm{min}, 0.049 \mathrm{~mm} / \mathrm{rev}, 2 \mathrm{~mm}$ and $0.8 \mathrm{~mm}$ respectively [5]. When dry turning $42 \mathrm{CrMo} 4$ material, surface roughness has minimum value when the cutting speed, depth of cut and feed rate are $110 \mathrm{~m} / \mathrm{min}, 2 \mathrm{~mm}$ and $0.214 \mathrm{~mm} / \mathrm{rev}$, respectively [6]. When turning EN8 steel, if the spindle speed, feed rate and depth of cut are 303 $\mathrm{rev} / \mathrm{min}, \quad 0.067 \mathrm{~mm} / \mathrm{rev}$ and $0.2 \mathrm{~mm}$, respectively, surface roughness has the minimum value [7]. For EN 354 steel, in order to obtain the minimum value of surface roughness, the feed rate, cutting speed and depth of cut during turning operation are respectively 0.015 $\mathrm{mm} / \mathrm{rev}, 222 \mathrm{~m} / \mathrm{min}$ and $1.2 \mathrm{~mm}$ [8]. For AM alloys, to reach the minimum value of surface roughness, the feed rate, cutting speed and depth of cut during turning process are respectively 0.1 $\mathrm{mm} / \mathrm{rev}, 115 \mathrm{~m} / \mathrm{min}$ and $0.5 \mathrm{~mm}$ [9]. The optimum values of cut depth, cutting speed and feed rate when turning AISI 1045 steel are 0.5 $\mathrm{mm}, 200 \mathrm{~m} / \mathrm{min}$ and $0.1 \mathrm{~mm} / \mathrm{rev}$, respectively. Upon machining in this condition, the surface roughness has the smallest value [10]. For S45C steel turning, surface roughness has the minimum value when the cutting speed, feed rate and depth of cut are $135 \mathrm{~m} / \mathrm{min}, 0.08 \mathrm{~mm} / \mathrm{rev}$ and $1.1 \mathrm{~mm}$, respectively [11]. When turning aluminum materials, surface roughness will be able to achieve the minimum value if the spindle speed, feed rate and depth of cut are $160 \mathrm{rev} / \mathrm{min}$, $0.05 \mathrm{~mm} / \mathrm{rev}$ and $1.5 \mathrm{~mm}$, respectively. Regarding Brass materials, the cutting parameters for the minimum of surface roughness are found to be $660 \mathrm{rev} / \mathrm{min}$ of the spindle speed, $0.1 \mathrm{~mm} / \mathrm{rev}$ of feed rate and 1.0 $\mathrm{mm}$ of depth of cut. Meanwhile, to earn the minimum of surface roughness of Copper, the spindle speed, feed rate and depth of cut are respectively $80 \mathrm{rev} / \mathrm{min}, 0.1 \mathrm{~mm} / \mathrm{rev}$ and $1.5 \mathrm{~mm}$ [12]. Surface roughness of S45C steel in turning operation will obtain the minimum value if the cutting speed, feed rate and depth of cut are 60 $\mathrm{m} / \mathrm{min}, 0.1 \mathrm{~mm} / \mathrm{rev}$ and $0.4 \mathrm{~mm}$, respectively [13]. To have the minimum value of surface roughness when turning Ti-6Al-4V Titanium Alloy, the depth of cut, feed rate and cutting speed are respectively $0.6 \mathrm{~mm}, 125 \mathrm{~m} / \mathrm{min}$ and 0.12 $\mathrm{mm} / \mathrm{rev}$ [14]. To achieve the minimum of surface roughness when turning AISI 1020 steel, the spindle speed, feed rate and depth of cut are respectively $630 \mathrm{rev} / \mathrm{min}, 0.05 \mathrm{~mm} / \mathrm{rev}$ and 1.25 $\mathrm{mm}$ [15]. Regarding Aluminium-2014 Alloy, surface roughness will be able to reach the smallest value when turning if the spindle speed, depth of cut and feed rate are respectively 1700 $\mathrm{rev} / \mathrm{min}, 0.4 \mathrm{~mm}$ and $35 \mathrm{~mm} / \mathrm{min}$ [16]. For AISI 409 steel turning, to have the minimum of surface roughness, the cutting speed, depth of cut and feed rate are respectively $400 \mathrm{~m} / \mathrm{min}, 2.0 \mathrm{~mm}$ and $0.2 \mathrm{~mm} / \mathrm{rev}$ [17]. To earn the maximum of MRR when turning thermoplastic polymer-delrin 500AL materials in turning operation, the spindle speed, feed rate and depth of cut are respectively $300 \mathrm{rev} / \mathrm{min}, 0.25 \mathrm{~mm} / \mathrm{rev}$ and $0.14 \mathrm{~mm}$ [18].

The Taguchi method is also combined with several other methods to optimize the turning process. A combination of Taguchi and Grey relational analysis (GRA) method found that surface roughness and MRR respectively obtain the minimum and maximum in turning process when the parameters is optimized at $400 \mathrm{~m} / \mathrm{min}$ of cutting speed, $0.1 \mathrm{~mm} / \mathrm{rev}$ of feed rate and $1.2 \mathrm{~mm}$ of cut depth [19]. Similarly, under this integrated approach, surface roughness is able to reach the minimum value in turning operation of EN-36 steel when the spindle speed, feed rate and depth of cut are respectively $598 \mathrm{rev} / \mathrm{min}, 0.15 \mathrm{~mm} / \mathrm{rev}$ and 1.5 $\mathrm{mm}$ [20]. This combination was also used in another study to determine optimization level of tool nose radius, tool rake angle, feed rate, cutting speed, cutting environment and depth of cut while turning unidirectional glass fiber reinforced plastic (UD-GFRP) composite. This study reveals that when machining in the cooled cutting environment, surface roughness is minimum and MRR is maximum if the tool nose radius, tool rake angle, feed rate, cutting speed and depth of cut are respectively $0.4 \mathrm{~mm}, \quad-6^{0}, 0.2 \mathrm{~mm} / \mathrm{rev}, 159.66$ 
$\mathrm{m} / \mathrm{min}, 1.4 \mathrm{~mm}$ [21]. Two other optimization methods, TOPSIS and SAW, are used with the Taguchi to identify the optimization level of the cutting speed, feed rate and depth of cut while turning Ti-6Al-4V alloy under minimum quantity lubrication (MQL). The aim of this paper is to minimize surface roughness, flank wear, cutting force and cutting temperature. The results indicated that the two methods TOPSIS and SAW respond similarly, the optimal values of the cutting speed, feed rate and depth of cut are $80 \mathrm{~m} / \mathrm{min}, 0.05$ $\mathrm{mm} / \mathrm{rev}$ and $0.1 \mathrm{~mm}$, respectively [22].

These studies show that the Taguchi method has been successfully applied to optimize the turning process in many specified conditions. However, the optimum values of the machining parameters for each type of material are found different. The combination of Taguchi method and others (GRA, TOPSIS, SAW, PSO) has also been efficiently used for optimizing turning operations. Nevertheless, there are likely no studies using the Taguchi method blended with the DEAR method to optimize the turning process.

The papers mentioned often choose surface roughness as the output. Some of them choose MRR and/or cutting force. AISI 1055 steel is common for the production of machined details in manufacturing engineering industry because of its good machinability and low cost. However, there have been no studies on multi-objective optimization of turning this steel considering all five outputs, which include surface roughness, three components of cutting force and MRR.

Hence, this study focuses on the Taguchi method combined with the Dear method in order to determine the optimal value of spindle speed, feed rate, depth of cut and tool nose radius while turning AISI 1055 steel to achieve the minimum surface roughness, minimum cutting force in 3 directions and maximum MRR. Influence of input parameters on output parameters is also analyzed in this study.

\section{DEAR METHOD}

DEAR is the method used for multi-objective optimization [23]. It is often combined with the Taguchi method. The Taguchi method is only able to solve the single-objective optimization problems based on the ratio $\mathrm{S} / \mathrm{N}$. Hence, in order to deal with multi-objective optimization problems, it is necessary to combine the Taguchi with another method, such as GRA, TOPSIS, SAW, PSO as described in the introduction. The mixture of the DEAR and Taguchi also overcome this limitation of the Taguchi [24].

The purpose of the experiment presented in this study is to have the minimum values of surface roughness $(R a)$ and the cutting force $(F x, F y, F z)$ and the maximum of $M R R$. Thus, it is necessary to solve the problem of multi-objective optimization. DEAR method is used in the research and performed in the following steps [25-27]:

- Determine the weights $(w)$ for each response for all experiments. Weight of response is the ratio of a response at any trial to the summation of all responses.

- Transform the data of response into weighted data by multiplying the observed data with its own weight.

- Divide the data as smaller the better with smaller the better.

- Treat this value as a multi response performance index (MRPI).

MRPI in the research is defined by the following formula:

$$
\begin{aligned}
M R P I= & W_{R_{a}} \cdot R_{a}+W_{F_{x}} \cdot F_{x}+W_{F_{y}} \cdot F_{y}+ \\
& W_{F_{z}} \cdot F_{z}+W_{M R R} \cdot M R R
\end{aligned}
$$

Where the weights are defined as:

$$
\begin{gathered}
W_{R_{a}}=\frac{R_{a}}{\sum R_{a}} \\
W_{F_{x}}=\frac{F_{x}}{\sum F_{x}} \\
W_{F_{y}}=\frac{F_{y}}{\sum F_{y}} \\
W_{F_{z}}=\frac{F_{z}}{\sum F_{z}} \\
W_{M R R}=\frac{1}{M R R} \\
\sum \frac{1}{M R R}
\end{gathered}
$$




\section{EXPERIMENT OF TURNING OPERATION}

\subsection{Material}

The material used in the experiment is AISI 1055 steel. This is a common material to manufacture machine details in the manufacturing engineering industry such as shafts, gears, and levers. The steel has high workability and its price is reasonable. Table 1 shows its designation according to several standards. Some properties of the steel are shown in Table 2. Table 3 introduces chemical composition of the steel. Test specimens have a length of $280 \mathrm{~mm}$ and their diameter of $28 \mathrm{~mm}$ (Fig. 1).

Table 1. Designation of AISI 1055 steel according to several standards

\begin{tabular}{|c|c|c|c|c|c|c|}
\hline USA & EU & Germany & Japan & France & England & Italy \\
\hline AISI & EN & DIN & JIS & AFNOR & BS & UNI \\
\hline 1055 & 1.0535 & C55 & S55C & C54 & En9 & 1 C55 \\
\hline Spain & China & Sweden & Poland & Czechia & Russia & Inter \\
\hline UNE & GB & SS & PN & CSN & GOST & ISO \\
\hline C55k & 55 & 1655 & 55 & 12060 & 50 & C55 \\
\hline
\end{tabular}

Table 2. Some properties of AISI 1055 steel

\begin{tabular}{|c|c|c|c|}
\hline $\begin{array}{c}\text { Youngs } \\
\text { module } \\
(\mathbf{G P a})\end{array}$ & $\begin{array}{c}\text { Poisson's } \\
\text { ratio }\end{array}$ & $\begin{array}{c}\text { Shear } \\
\text { module } \\
(\mathbf{G P a})\end{array}$ & $\begin{array}{c}\text { Density } \\
\left(\mathbf{k g} / \mathbf{m}^{3}\right)\end{array}$ \\
\hline 210 & 0.3 & 80 & 7800 \\
\hline $\begin{array}{c}\text { Average } \\
\mathbf{C T E ~ 2 0 -} \\
\mathbf{3 0 0}^{\circ} \mathbf{C} \\
\left(\boldsymbol{\mu \mathbf { m }} / \mathbf{m}^{\circ} \mathbf{K}\right)\end{array}$ & $\begin{array}{c}\text { Specific heat } \\
\text { capacity } \mathbf{5 0} /_{\mathbf{1 0 0}^{\circ} \mathbf{C}}^{\left(\mathbf{J}^{\prime} \mathbf{k g}^{\circ} \mathbf{K}\right)}\end{array}$ & $\begin{array}{c}\text { Thermal } \\
\text { conductivity } \\
\text { Ambient } \\
\text { temperature } \\
\left(\mathbf{W} / \mathbf{m}^{\circ} \mathbf{K}\right)\end{array}$ & $\begin{array}{c}\text { Electrical } \\
\text { resistivityA } \\
\text { mbient } \\
\text { temperature } \\
(\boldsymbol{\mu} \Omega \mathbf{m})\end{array}$ \\
\hline 12 & $460-480$ & $40-45$ & $0.20-0.25$ \\
\hline
\end{tabular}

Table 3. Chemical composition of AISI 1055 steel

\begin{tabular}{|c|c|c|c|c|c|c|}
\hline Element & $\mathbf{C}$ & $\mathbf{S i}$ & $\mathbf{M n}$ & $\mathbf{C r}$ & $\mathbf{A l}$ & $\mathbf{C u}$ \\
\hline$\%$ & 0.55 & 0.25 & 0.7 & 0.1 & 0.02 & 0.1 \\
\hline
\end{tabular}

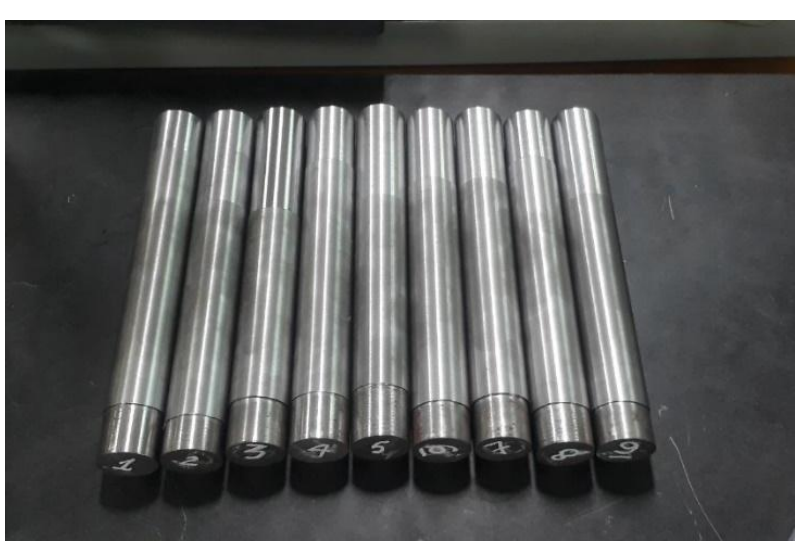

Fig. 1. Test specimens

\subsection{Lathe and cutting tools}

The cutting tools used in the experiment are titanium-coated from Lungaloy (Japan). Their tool nose radii are $0.2 \mathrm{~mm}, 0.4 \mathrm{~mm}$ and $0.6 \mathrm{~mm}$. A FEL1440GMW conventional lathe from MAGNUM-CUT (Taiwan) is used for experimental purposes (Fig. 2).

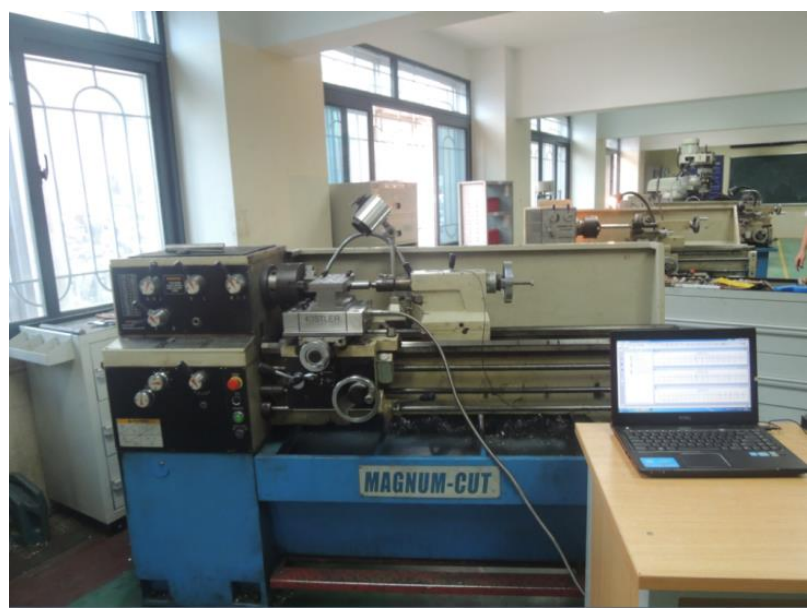

Fig. 2. The conventional lathe

\subsection{Experiment design}

The four parameters chosen are the input of the experiment, including spindle speed, feed rate, depth of cut, tool nose radius. Three levels of each parameter were considered as shown in Table 4. The 9 experiments (L9) were designed based on the Taguchi orthogonal array, shown in Table 5.

Table 4. Levels of parameters

\begin{tabular}{|c|c|c|c|c|c|}
\hline \multirow{2}{*}{ Parameter } & \multirow{2}{*}{ Symbols } & \multirow{2}{*}{ Unit } & \multicolumn{3}{|c|}{ Levels } \\
\cline { 4 - 6 } & & & $\mathbf{1}$ & $\mathbf{2}$ & $\mathbf{3}$ \\
\hline Spindle speed & $n$ & $\mathrm{rev} / \mathrm{min}$ & 460 & 650 & 910 \\
\hline Feed rate & $f$ & $\mathrm{~mm} / \mathrm{rev}$ & 0.08 & 0.194 & 0.302 \\
\hline Depth of cut & $t$ & $\mathrm{~mm}$ & 0.20 & 0.35 & 0.50 \\
\hline Tool nose radius & $r$ & $\mathrm{~mm}$ & 0.2 & 0.4 & 0.6 \\
\hline
\end{tabular}

Table 5. L9 orthogonal array with input parameters

\begin{tabular}{|c|c|c|c|c|c|c|c|c|}
\hline \multirow{2}{*}{$\begin{array}{c}\text { Trial } \\
\text { No. }\end{array}$} & \multicolumn{3}{|c|}{ Code value } & \multicolumn{5}{c|}{ Actual value } \\
\hline 1 & 1 & 1 & 1 & 1 & 460 & 0.08 & 0.20 & 0.2 \\
\hline 2 & 1 & 2 & 2 & 2 & 460 & 0,194 & 0.35 & 0.4 \\
\hline 3 & 1 & 3 & 3 & 3 & 460 & 0.302 & 0.50 & 0.6 \\
\hline 4 & 2 & 1 & 2 & 3 & 650 & 0.08 & 0.35 & 0.6 \\
\hline 5 & 2 & 2 & 3 & 1 & 650 & 0.194 & 0.50 & 0.2 \\
\hline 6 & 2 & 3 & 1 & 2 & 650 & 0.302 & 0.20 & 0.4 \\
\hline 7 & 3 & 1 & 3 & 2 & 910 & 0.08 & 0.50 & 0.4 \\
\hline 8 & 3 & 2 & 1 & 3 & 910 & 0.194 & 0.20 & 0.6 \\
\hline 9 & 3 & 3 & 2 & 1 & 910 & 0,302 & 0.35 & 0.2 \\
\hline
\end{tabular}




\subsection{Measuring instrument}

\subsubsection{Surface roughness measuring instrument}

Surface roughness measuring machine SJ-301 from Mitutoyo (Japan) was used to measure the roughness of the test components (Fig. 3). Its order number, detector number and stylus tip radius are 178-953-2, 178-390 and $5 \mu \mathrm{m}$, respectively. Each sample had a standard length of $0.8 \mathrm{~mm}$ and was measured at least 3 times. The roughness value of each experiment is the average of the successive measurements.

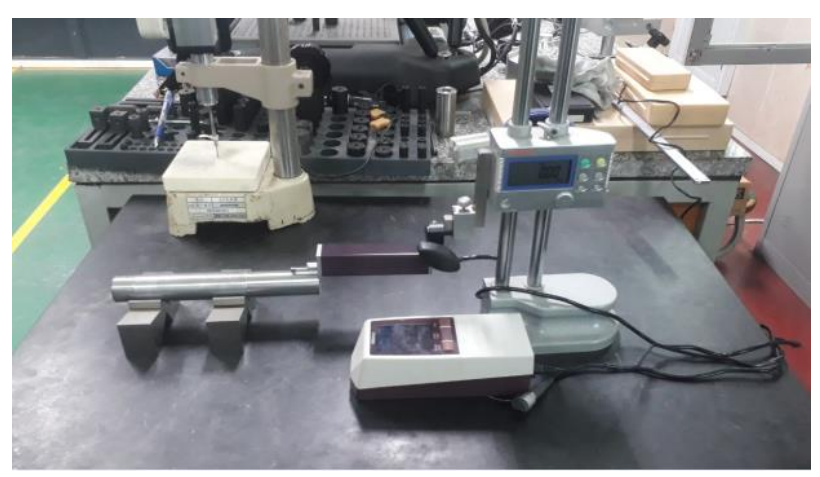

Fig. 3. Surface roughness tester

\subsubsection{Force measuring instrument}

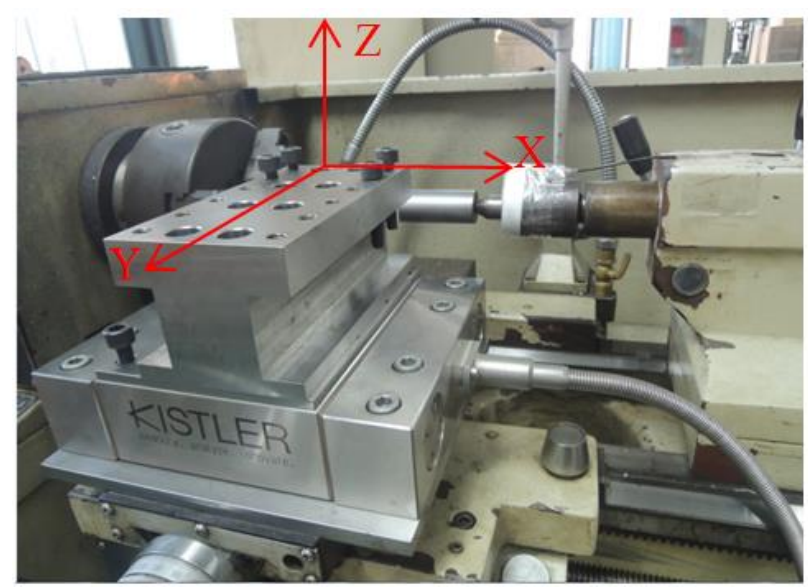

a) Dynamometer

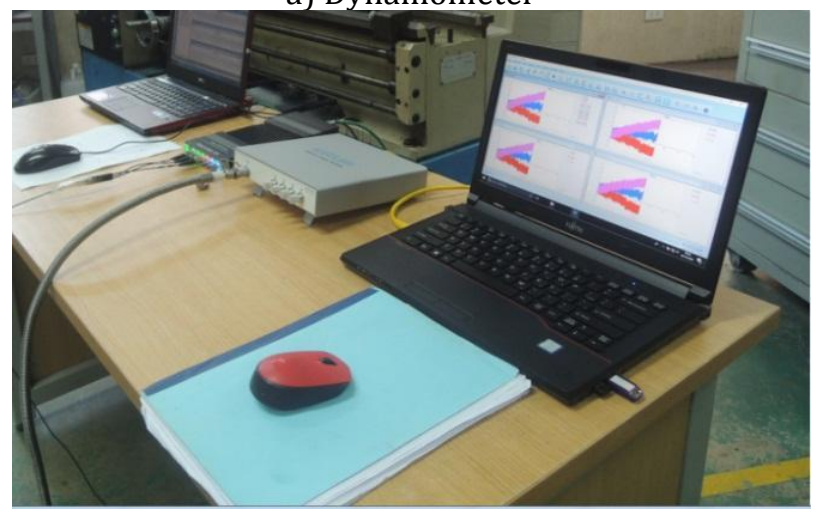

b) The data-processing devices and computer

Fig. 4. Cutting force measuring instrument
The cutting force measuring device used in the study is a three-component dynamometer from KISTLER (Switzerland). Its model number is 9129AA. The device is capable of measuring up to $5 \mathrm{kN}$ for component forces in the $\mathrm{X}$ and $\mathrm{Y}$ directions and $30 \mathrm{kN}$ for component force in the $\mathrm{Z}$ direction. The dynamometer is fixed on carriage (Fig. 4). The dataprocessing devices were connected to the computer and they processed the results of the measurement of the component forces by the dynamometer. The value of the forces at each experiment is the average during the machining operation.

\subsubsection{Determination of MRR}

Material removal rate is defined as:

$$
M R R=\frac{1}{60} \cdot n \cdot \pi \cdot d \cdot f \cdot t \quad\left(\mathrm{~mm}^{3} / \mathrm{s}\right)
$$

Where:

$n$ is spindle speed (rev/min).

$d$ is diameter of workpiece $(\mathrm{mm})$.

$f$ is feed rate $(\mathrm{mm} / \mathrm{rev})$.

$t$ is depth of cut (mm).

\subsection{Result and discussion}

Experiment results are presented in Table 6. Pareto chart of the influence of input parameters on output parameters is shown in Figures 5 to 8.

Table 6. Result of the experiments

\begin{tabular}{|c|c|c|c|c|c|}
\hline $\begin{array}{c}\text { Trial } \\
\text { No. }\end{array}$ & $\boldsymbol{R a}(\boldsymbol{\mu m})$ & $\begin{array}{c}\boldsymbol{F x} \\
(\mathbf{N})\end{array}$ & $\begin{array}{c}F y \\
(\mathbf{N})\end{array}$ & $\begin{array}{c}F \mathbf{N z} \\
(\mathbf{N})\end{array}$ & $\begin{array}{c}\boldsymbol{M R R} \\
\left(\mathbf{m m}^{3} \mathbf{s} \mathbf{s}\right.\end{array}$ \\
\hline 1 & 1,344 & 94,749 & 218,941 & 94,964 & 10,790 \\
\hline 2 & 0,968 & 184,704 & 307,095 & 85,576 & 45,791 \\
\hline 3 & 1,030 & 626,367 & 1286,969 & 275,913 & 101,834 \\
\hline 4 & 1,795 & 243,559 & 447,649 & 115,240 & 26,683 \\
\hline 5 & 1,070 & 169,184 & 255,388 & 69,449 & 92,436 \\
\hline 6 & 1,029 & 194,803 & 282,244 & 79,465 & 57,558 \\
\hline 7 & 0,994 & 212,316 & 400,216 & 83,109 & 53,365 \\
\hline 8 & 1,166 & 236,584 & 410,505 & 106,411 & 51,764 \\
\hline 9 & 1,080 & 138,854 & 143,253 & 72.981 & 141,018 \\
\hline
\end{tabular}

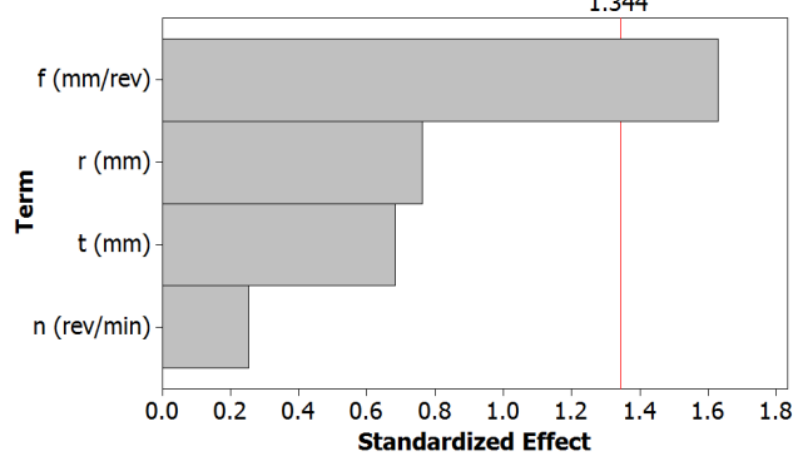

Fig. 5. Pareto chart of the influence of the input parameters on $R a$ 


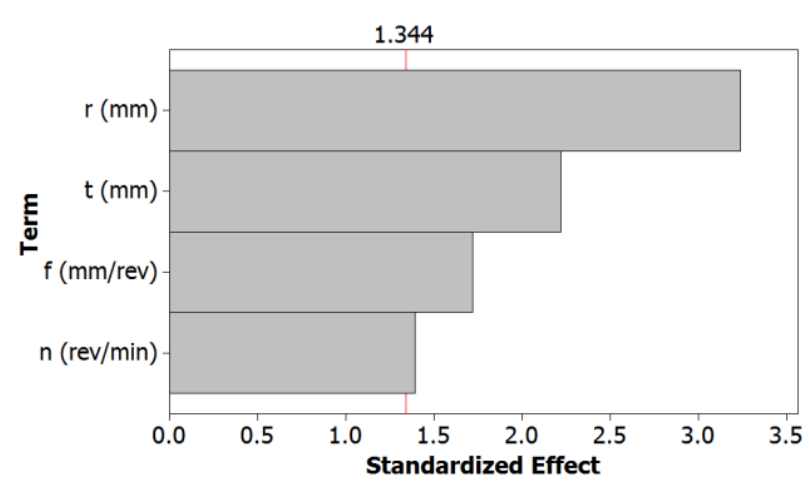

Fig. 6. Pareto chart of the influence of the input parameters on $F x$

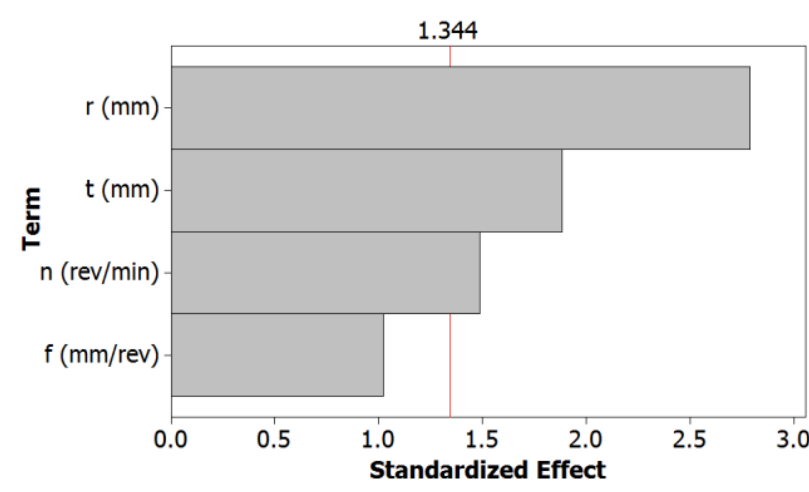

Fig. 7. Pareto chart of the influence of the input parameters on $F y$

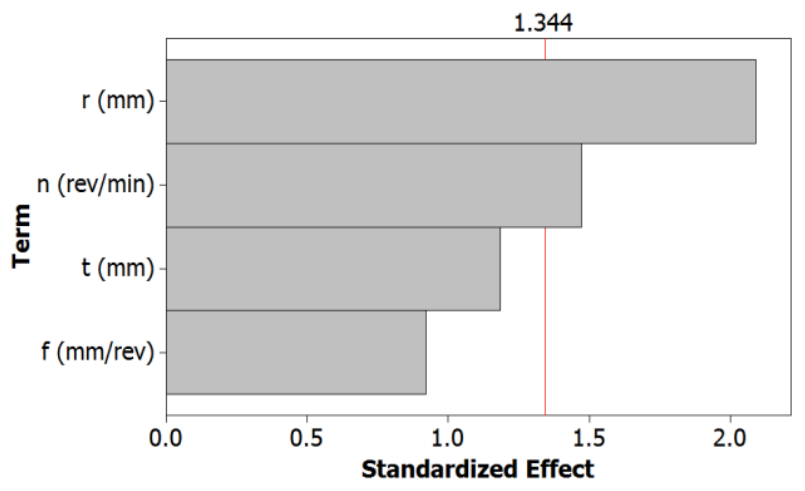

Fig. 8. Pareto chart of the influence of the input parameters on $\mathrm{FZ}$

Figures 5 to 8 indicate that:

- The feed rate has a significant impact on surface roughness, while the other parameters are negligible to it (because the line showing their influence on surface roughness does not exceed across the red limit line in the Pareto chart). However, when considering in detail, effect of the tool nose radius on surface roughness is greater than depth of cut, while spindle speed is the parameter with the least influence.
- All four input parameters have a significant impact on the X-direction component force and the degree of influence decreases in order of tool nose radius, depth of cut, feed rate and spindle speed.

- Regarding component force Fy, the tool nose radius is the most influential, followed by depth of cut, spindle speed and feed rate is negligible to it.

- The tool nose radius and spindle speed both considerably affect the component force in the $\mathrm{z}$ direction, on which the impact of the tool tip radius is greater than the spindle speed. The other two parameters are not noticeable to $F z$.

Since MRR is calculated based on (7), it is clear that all parameters of the spindle speed, feed rate and depth of cut influence on the MRR. Increasing the value of these parameters increases the MRR.

Analyses above show that the effects of the input parameters on the output parameters are not the same. For example, the tool nose radius is significant to all three component cutting forces but unimportant to surface roughness, while the feed rate has the greatest impact on surface roughness. The spindle speed is a parameter that negligibly affects surface roughness but greatly influences all three of component cutting forces, etc. The data in Table 6 reveals that the surface roughness are minimum at trial No.2; the component forces $F x, F y, F z$ have the smallest value in trial No.1, No.9 and No.5 respectively; the MRR reaches the highest value in trial No.9. Therefore, in order to identify the desired cutting parameters for achieving the "minimum" of surface roughness and cutting forces and the "maximum" of MRR, it is necessary to solve the multi-objective optimization problem, in which the spindle speed, the feed rate, the depth of the cut and the tool nose radius are parameters to be defined.

\subsection{Multi-objective optimization of turning operation using Dear method}

Based on the results in Table 6, the weights of the responses and the MRPI values in each experiment were defined by formula from (1) to (6), as presented in Table 7. 
Table 7. Weights of the responses and the MRPI values in each experiment

\begin{tabular}{|c|c|c|c|c|c|c|}
\hline \multirow{2}{*}{ Trial No. } & \multicolumn{7}{|c|}{ Weight } & \multirow{2}{*}{ MRPI } \\
\cline { 2 - 6 } & $\boldsymbol{R a}$ & $\boldsymbol{F} \boldsymbol{F}$ & $\boldsymbol{F y}$ & $\boldsymbol{F z}$ & $\boldsymbol{M R R}$ & \\
\hline 1 & 0.12829 & 0.04509 & 0.05835 & 0.09660 & 0.39412 & 30.64574 \\
\hline 2 & 0.09240 & 0.08791 & 0.08184 & 0.08705 & 0.09287 & 53.16138 \\
\hline 3 & 0.09832 & 0.29811 & 0.34299 & 0.28065 & 0.04176 & 709.9278 \\
\hline 4 & 0.17134 & 0.11592 & 0.11930 & 0.11722 & 0.15937 & 99.70661 \\
\hline 5 & 0.10214 & 0.08052 & 0.06806 & 0.07064 & 0.04601 & 40.27302 \\
\hline 6 & 0.09822 & 0.09271 & 0.07522 & 0.08083 & 0.07388 & 50.06805 \\
\hline 7 & 0.09488 & 0.10105 & 0.10666 & 0.08454 & 0.07969 & 75.51397 \\
\hline 8 & 0.11130 & 0.11260 & 0.10940 & 0.10824 & 0.08215 & 87.44938 \\
\hline 9 & 0.10309 & 0.06609 & 0.03818 & 0.07423 & 0.03016 & 24.42696 \\
\hline
\end{tabular}

MRPIs of the initial cutting parameters were determined. They are the summation of MRPI of each parameter at the respective levels, shown in Table 8.

Table 8. Summation of MRPI at each level of cutting parameters

\begin{tabular}{|c|c|c|c|c|}
\hline \multirow{2}{*}{ Par. } & \multicolumn{3}{|c|}{ Levels } & \multirow{2}{*}{ Max-Min } \\
\cline { 2 - 5 } & $\mathbf{1}$ & $\mathbf{2}$ & $\mathbf{3}$ & \\
\hline$n$ & 793.7349 & 190.0477 & 187.3903 & 606.3446 \\
\hline$f$ & 205.8663 & 180.8838 & 784.4228 & 603.5390 \\
\hline$t$ & 168.1632 & 177.2949 & 825.7148 & 657.5517 \\
\hline$r$ & 95.34572 & 178.7434 & 897.0838 & 801.7381 \\
\hline
\end{tabular}

The data in Table 8 show that the MRPI of spindle speed, feed rate, depth of cut and tool nose radius are minimum at level 3, 2, 1, 1 respectively. In the DEAR method, the value of input parameter corresponding to the minimum MRPI is the most optimal [25, 28]. Thus, the optimal input parameters include $n(910 \mathrm{rev} / \mathrm{min}), f(0.194$ $\mathrm{mm} / \mathrm{rev}), t(0.2 \mathrm{~mm})$ and $r(0.2 \mathrm{~mm})$. The greatest "Max - Min" value of MRPI is 801.7381, which is also the tool nose radius. Furthermore, the input parameters corresponding to the maximum of "Max-Min" of MRPI have the greatest influence on the efficiency of the entire turning process $[25,28]$. Thus, when assessing the turning process by considering surface roughness, cutting force in three directions $(\mathrm{X}, \mathrm{Y}, \mathrm{Z})$ and $M R R$, the tool nose radius is found to be the most influential parameter, followed by depth of cut and spindle speed. The feed rate affects the turning operation least.

\subsection{Experiments using the optimal cutting parameters}

The above optimal values of the input parameters are used for the turning process $(910 \mathrm{rev} / \mathrm{min}$ of $n$, $0.194 \mathrm{~mm} / \mathrm{rev}$ of $f, 0.2 \mathrm{~mm}$ of $t$ and $0.2 \mathrm{~mm}$ of $r$ ).
Surface roughness and component cutting forces are measured in each test, $M R R$ is also defined in each case. The result is presented in table 9.

Table 9. Output parameters with optimum values of input parameters

\begin{tabular}{|c|c|c|c|c|c|}
\hline $\begin{array}{c}\text { Trial } \\
\text { No. }\end{array}$ & $\begin{array}{c}\text { Ra } \\
(\boldsymbol{\mu m})\end{array}$ & $\begin{array}{c}\mathbf{F x} \\
\mathbf{( N )}\end{array}$ & $\begin{array}{c}\mathbf{F y} \\
\mathbf{( N )}\end{array}$ & $\begin{array}{c}\mathbf{F z} \\
\mathbf{( N )}\end{array}$ & $\begin{array}{c}\text { MRR } \\
\left(\mathbf{m m}^{\mathbf{3}} \mathbf{/ s}\right)\end{array}$ \\
\hline 1 & 0.985 & 114.522 & 162.852 & 80.772 & 51.764 \\
\hline 2 & 1.022 & 113.560 & 160.288 & 82.288 & 51.764 \\
\hline 3 & 0.981 & 109.922 & 159.386 & 78.776 & 51.764 \\
\hline Mean & 0.996 & 112.668 & 160.842 & 80.612 & 51.764 \\
\hline
\end{tabular}

The comparison of data between table 9 and table 6 shows that the value of the output parameters is significantly improved when the optimal of the input parameters is applied.

\section{CONCLUSION}

In this study, experiments of turning AISI 1055 steel with a titanium coated cutting tool are performed. In each test, surface roughness and three component cutting forces are measured and MRR is identified. The combination of the Taguchi and DEAR method determines the value of the input parameters for reaching the "minimum" of surface roughness and component cutting forces and the "maximum" of MRR. Some conclusions are drawn as follows:

- The feed rate is the parameter that has a significant impact on the surface roughness, while the spindle speed, depth of cut and tool nose radius have negligible effects on it.

- All four of the input parameters are considerable to $F X$, in which the tool nose radius is the most influential, followed by the depth of cut and the feed rate. The least is the spindle speed. 
- The tool nose radius greatly impacts on Fy, followed by depth of cut and the spindle speed. Meanwhile, the feed rate has a limited influence on Fy.

- Regarding $F z$, the tool nose radius has the greatest effect on it, followed by the spindle speed. The depth of cut and feed rate are inconsiderable to $\mathrm{Fz}$.

- The optimal cutting parameters include spindle speed $n$ (910 rev/min), feed rate $f(0.194$ $\mathrm{mm} / \mathrm{rev})$, depth of cut $t(0.2 \mathrm{~mm})$ and tool nose radius $r(0.2 \mathrm{~mm})$.

- Among these four parameters, the tool nose radius is the most influential parameter in the turning process (considering the output factors, including surface roughness, three component cutting forces and MRR).

- When machining with the optimum parameters, the output is significantly improved.

- Apparently, the algorithms of the DEAR method are successfully applied for multi-objective optimization of not only turning operation in this study, but also other machining processes.

\section{Acknowledgment}

Financial support from the Hanoi University of Industry for this research is acknowledged with gratitude.

\section{REFERENCES}

[1] T.V. Dich, N. T. Binh, N. T. Dat, N. V. Tiep, T. X. Viet, Manufacturing technology, Science and Technics Publishing House, Hanoi, Vietnam, 2003.

[2] M.A. Habib, Md.A.U. Patwari, K.A. Khan, A.N.M.A. Tomal, Surface Roughness Optimization in Turning Operation Using Hybrid Algorithm of Artificial Bee Colony with RSM, Advanced Materials Research, vol. 1101, pp. 393-396, 2015, doi:10.4028/www.scientific.net/AMR.1101.393

[3] M.H. Tanvir, A.Hussain, M.M.T. Rahman, S. Ishraq, K. Zishan, S.K.T.T. Rahul, M.A. Habib, MultiObjective Optimization of Turning Operation of Stainless Steel Using a Hybrid Whale Optimization Algorithm, Journal of Manufacturing and Materials Processing, vol. 4, iss. 3, pp. 1-14, 2020, doi: 10.3390/jmmp4030064
[4] P.K. Sahu, N.K. Sahu, A. Dubey, Optimization of cutting parameters by turning operation in lathe machine, International Journal of Mechanical And Production Engineering, vol. 5, iss. 11, pp. 46-51, 2017.

[5] D. Lazarević, M. Madić, P. Janković, A. Lazarević, Cutting Parameters Optimization for Surface Roughness in Turning Operation of Polyethylene (PE) Using Taguchi Method, Tribology in Industry, vol. 34, iss. 2, pp. 68-73, 2012.

[6] M. Dragičević, E. Begović, I. Peko, Optimization of dry turning process parameters using Taguchi method combine with Fuzzy logic approach, Proceedings on Engineering Sciences, vol. 1, no.1, pp. 429-435, 2019, doi: 10.24874/PES01.01.056

[7] S. Banerjee, S. Kundu, S. Choudhury, A. Chatterjee, Process parameter optimization in lathe turning operation to improve the surface roughness and reduce the cutting force using Taguchi method, International journal of innovations in engineering research and technology, vol. 8, iss. 4, pp. 1-8, 2017.

[8] S. Kajal, S. Yadav, Optimization of CNC Turning Parameters for Surface Roughness on EN 354 Steel using Taguchi Method, Journal of Material Science and Mechanical Engineering, vol. 2, iss. 10, pp. 54-57, 2015.

[9] S. Dutta, S.K.R. Narala, Optimizing turning parameters in the machining of AM alloy using Taguchi Methodology, Measurement, vol. 169, 2021, doi: 10.1016/j.measurement.2020.108340

[10] K. Chomsamutr, S. Jongprasithporn, The Cutting Parameters Design for Product Quality Improvement in Turning Operations: Optimization and Validation with Taguchi Method, The 40th International Conference on Computers \& Industrial Engineering, Awaji, pp. 1-6, 2010, doi: 10.1109/ICCIE.2010.5668340

[11] W.H. Yang, Y.S. Tarng, Design optimization of cutting parameters for turning operations based on the Taguchi method, Journal of Materials Processing Technology, vol. 84, iss. 1-3, pp. 122-129, 1998, doi: 10.1016/S0924-0136(98)00079-X

[12] S.K. Patod, S. Sharma, Optimization of CNC Turning Cutting Parameter for Geometrical Dimensional Accuracy with Surface roughness on the non-ferrous Material Applying Taguchi Technique, International Journal of Engineering Trends and Technology, vol. 67, iss. 12, pp. 56-66, 2019.

[13] N. Saraswat, A. Yadav, A. Kumar, B.P. Srivastava, Optimization of Cutting Parameters in Turning Operation of Mild Steel, International Review of Applied Engineering Research, vol. 4, no. 3, pp. 251256, 2014. 
[14] S.P. Shahebrahimi, A. Dadvand, Optimization of Cutting Parameters for Turning Operation of Titanium Alloy Ti-6Al-4V Material Workpiece using the Taguchi Method, Advanced Materials Research, vol. 685, 57-62, 2013, doi: 10.4028/www.scientific.net/AMR.685.57

[15] D. Sonowal, D. Sarma, P.B. Barua, T. Nath, Taguchi Optimization of Cutting Parameters in Turning AISI 1020 MS with M2 HSS Tool, IOP Conference Series: Materials Science and Engineering, vol. 225, pp. 1-12, 2017, doi: 10.1088/1757899X/225/1/012186

[16] A. Aswal, A. Jha, A. Tiwari, Y. K. Modi, CNC Turning Parameter Optimization for Surface Roughness of Aluminium Alloy Using Taguchi Methodology, Journal Européen des Systèmes Automatisés, vol. 52, no. 4, pp. 387-390, 2014, doi: 10.18280/jesa.520408

[17] M. ÖZDEMIR, Optimization with Taguchi Method of Influences on Surface Roughness of Cutting Parameters in CNC Turning Processing, Mechanika, vol. 25, iss. 5, pp. 397-405, 2019, doi:10.5755/j01.mech.25.5.23005

[18] M.A.I. Upletawala, T. Katratwar, Optimization of Cutting Parameters for Turning Operation on Thermoplastic Polymer-Delrin 500AL, International Journal of Innovative Research in Science,Engineering and Technology, vol. 5, iss. 8, pp. 15545-15553, 2016.

[19] F. Puh, Z. Jurkovic, M. Perinic, M. Brezocnik, S. Buljan, Optimizacija parametara obrade tokarenja s više kriterija kvalitete uporabom Grey relacijske analize, Technical gazette, vol. 23, iss.2, pp. 377-382, 2016, doi: 10.17559/TV20150526131717

[20] S.K. Madhavi, D. Sreeramulu, M. Venkatesh, Optimization of turning process parameters by using grey-Taguchi, International Journal of Engineering, Science and Technology, vol. 7, no. 4, pp. 1-8, 2015.

[21] M. Gupta, S. Kumar, Multi-objective optimization of cutting parameters in turning using grey relational analysis, International Journal of Industrial Engineering Computations, vol. 4, pp. 547-558, 2013, doi: 10.5267/j.ijiec.2013.06.001

[22] R. Singh, J.S. Dureja, M. Dogra, J.S. Randhawa, Optimization of machining parameters under $M Q L$ turning of Ti-6Al-4V alloy with textured tool using multi-attribute decision-making methods, World Journal of Engineering, vol. 16, iss. 5, pp. 648-659, 2019, doi: 10.1108/WJE-06-2019-0170

[23] M. Manoj, G.R. Jinu, T. Muthuramalingam, Multi response optimization of AWJM process Parameterson machining $\mathrm{TiB}_{2}$ particles reinforced Al7075 composite using Taguchi-DEAR methodology, Silicon, vol. 10, pp. 2287-2293, 2018, doi: 10.1007/s12633-018-9763-x

[24] H.C. Liao, Y.K. Chen, Optimizing multi-response problem in the Taguchi method by DEA based ranking method, International Journal of Quality \& Reliability Maganement, vol. 19, iss.7, pp. 825837, 2002, doi: 10.1108/02656710210434766

[25] V.V. Reddy, C.S. Reddy, Multi Response Optimization of EDM of AA6082 Material using Taguchi- DEAR Method, International Journal of Scientific \& Engineering Research, vol. 7, iss. 6, pp. 215-219, 2016.

[26] T. Muthuramalingam, S. Vasanth, M. M. Rabik, T. Geethapriyan, A. Ramamurthy, Multi Response Optimization of EDM Process Parameters using Assignments of Weight Method, International Journal of Engineering Research \& Technology, vol 4. iss. 26, pp. 1-3, 2016.

[27] M.J. Sandeep, G.C.P. Manjunath, R.C. Ganesh, B.P. Mahesh, U.M. Daivagna, Multi Response Optimization of Green Sand Moulding Parameters Using Taguchi-DEAR Method, Applied Mechanics and Materials, vol. 895, pp. 1-7, 2019, doi: 10.4028/www.scientific.net/AMM.895.1

[28] N.T. Nguyen, D.D. Trung, A study on the surface grinding process of the SUJ2 steel using CBN slotted grinding wheel, AIMS Materials Science, vol. 7, iss. 6, pp. 871-886, 2020, doi: 10.3934/matersci.2020.6.871 